\title{
Performance and kinematics of saltation in the limbless lizard Ophisaurus attenuatus (Squamata: Anguidae)
}

\author{
Emma D. Wass and Gary W. Gerald \\ Biology Department, Nebraska Wesleyan University, Lincoln, Nebraska 68504, USA. \\ E-mail: equestrianemma285@gmail.com,ggerald@nebrwesleyan.edu.
}

\begin{abstract}
Performance and kinematics of saltation in the limbless lizard Ophisaurus attenuatus (Squamata: Anguidae). Saltation has been observed in several species of snakes and limbless lizards, and is most often used as an escape tactic during encounters with predators. However, studies examining kinematics and performance in limbless lizards are scarce and limited to observations of single individuals. We analysed 34 jump sequences from eight individual Ophisaurus attenuatus that exhibited escape saltation following minimal handling. We found that jumping is kinematically different from that described in snakes and similar to one other limbless lizard. Eight jumps resulted in the body completely leaving the ground. These jumps were characterized by larger displacement distances but were similar in speed compared to other jumps. Body mass was positively related to jump speed, but not with jump distances. This study suggests that increases in force production capabilities with increasing mass and the hindering effects of gravity interact to determine saltation performance in limbless lizards.
\end{abstract}

Keywords: escape behavior, jumping, limb-reduced, speed, take-off, Western Slender Glass Lizards.

\begin{abstract}
Resumo
Desempenho e cinemática do salto no lagarto ápode Ophisaurus attenuatus (Squamata: Anguidae). O salto foi observado em várias espécies de serpentes e lagartos ápodes. sendo mais utilizado como uma tática de fuga durante encontros com predadores. Contudo, estudos examinando a cinemática e o desempenho em lagartos ápodes são escassos e limitados a observações de indivíduos isolados. Analisamos 34 sequências de salto de oito indivíduos de Ophisaurus attenuatus que exibiram fuga aos saltos após manipulação mínima. Verificamos que o salto é cinematicamente diferente do que foi descrito para serpentes e similar ao que foi descrito para um outro lagarto ápode. Oito saltos resultaram na elevação total do corpo do lagarto do substrato. Esses saltos foram caracterizados por maiores distâncias de deslocamento, mas foram similares em velocidade aos outros saltos. A massa corpórea foi positivamente relacionada à velocidade, mas não relacionada às distâncias do salto. Este estudo sugere que, em lagartos ápodes, o aumento da capacidade de produção de força relacionado ao aumento de massa interage com os efeitos restritivos da gravidade na determinação do desempenho no salto.
\end{abstract}

Palavras-chave: comportamento de fuga, decolagem, lagarto-de-vidro-delgado-do-oeste, redução apendicular, velocidade.

Received 19 January 2017

Accepted 24 May 2017

Distributed June 2017 


\section{Introduction}

Saltation, or jumping, is an important behavior utilized by some reptiles for movement through complex habitats or escaping a predation attempt. It is well studied in some limbed lizards (e.g., Anolis), where it is commonly used to move from branch to branch in arboreal habitats (e.g., Losos and Irschick 1996, Mattingly and Jayne 2004). This movement involves using primarily the hindlimb to generate the force needed for take-off (Toro et al. 2004). Saltation in limbless reptiles, however, is an important escape behavior that has been rarely studied (Pianka and Vitt 2003).

The majority of reports on jumping behaviors in snakes and limbless lizards are simply observations (reviewed in Gans 1974, Bartholomew and Nohavec 1995, Pianka and Vitt 2003, Socha 2011). In snakes, saltation has been described as an exaggerated defensive strike for which the body briefly leaves the ground due to the momentum of the head and body (Lillywhite 2014). Smaller individual $(<23.5 \mathrm{~g})$ horned adders [Bitis caudalis (Smith, 1839)] have been shown to utilize sidewinding to jump via accelerating the body while pushing with the tail, which results in traveling through the air for roughly four-fifths the length of the body (Gans and Mendelssohn 1972, Gans 1974). Bartholomew and Nohavec (1995) reported a Mojave rattlesnake (Crotalus scutulatus Kennicott, 1861) that defensively jumped at a person using only one point of contact with the ground by the tail in what was described as a derivative of concertina locomotion. A specialized form of jumping from branches for gliding purposes occurs in flying snakes [Chrysopelea paradisi Boie, 1827, C. ornata (Shaw, 1802), and $C$. pelias (Linnaeus, 1758)] and the closely-related, non-gliding bronzeback snake [Dendrelaphis pictus (Gmelin, 1789)] (Socha 2006, 2011). Additionally, amphisbaenians are able to jump defensively using the tip of the tail to make static contact and then rapidly convulsing their bodies in s-shaped curves (Gans 1974).
In limbless or limb-reduced lizards, saltation has been reported in a few species representing three different families (Pygopodidae, Gymnophthalmidae, Anguidae) but is poorly studied (Pianka and Vitt 2003). To our knowledge, Bauer (1986) has conducted the only detailed study of saltation in a limbless lizard (Delma tincta De Vis, 1888). The jump of this species was found to last less than half a second and involved the production of a rapidly oscillating sine wave that propagated the body posteriorly through two points of substrate contact by the tail (Bauer 1986). The jumping sequences observed in $D$. tincta differ from that of other limbless reptiles in that lateral displacement of the body following the jump did not always occur and the pattern of static contact by the tail during take-off differed by propelling the body forward at $45^{\circ}$ from the substrate (Bauer 1986).

The primary aim of this study is to quantify and describe the kinematics and performance of saltation by the Western Slender Glass Lizard, Ophisaurus attenuatus Baird, 1880, and examine the influence of body size on these variables. Although saltation has been briefly reported in this species (Cliburn 1957), no study has provided a detailed description and analysis of jumping by multiple individuals.

\section{Materials and Methods}

Eight sub-adult or adult $O$. attenuatus (mass 3.0-20.4 g; SVL 8.0-15.5 cm; tail length 15.5$29.5 \mathrm{~cm}$ ) were captured on 26 and 27 June 2010 while crossing roads in Ellis and Russell counties, Kansas, USA, and transported to the laboratory for use in a study on locomotor performance. Lizards were placed in individual plastic containers with commercial terrarium bedding consisting of red Cyprus mulch with a water dish and hidebox. Heat pads placed on one side of the container created a thermal gradient (ca. $25-35^{\circ} \mathrm{C}$ ) in the enclosure. After several days, preliminary locomotor trials were attempted on several individuals. During trials, lizards were observed jumping in an attempt to 
escape the track used to assess locomotor performance. Lizards would continuously jump (up to six times) before moving. Therefore, lizards were placed in aquaria to videotape jumping sequences in order to quantify and describe the mechanics of the jumping behavior approximately one week after being housed in the laboratory.

Individuals were videotaped (Sony DCRTRV460, Digital8) at 30 frames/s after being placed in a 37.9-liter aquarium containing terrarium carpet (Eco Carpet: Zoo Med). The camera was positioned horizontally with the tank to record a side view of the behavior. A piece of white Plexiglass was placed in the tank to (1) provide a light background to more easily observe individuals during video playback and (2) to limit the space available in the aquarium for the lizard to move, which improved the clarity of the sequences. Consequently, lizards could move and jump within a $50.8 \times 12.0 \times$ $33.0 \mathrm{~cm}$ space. Lizards often jumped after being immediately placed in the tank. Once jumping stopped, the experimenter's hand reached to touch the tail and "chase" the lizard to stimulate additional jumps. After 1 min of "chasing," the lizard was returned to its enclosure if it no longer jumped. Although not all lizards jumped the same number of times, we attempted to record as many jumps as possible from each individual. All jumps occurred at $25 \pm 2{ }^{\circ} \mathrm{C}$.

For each jump, we measured average speed $(\mathrm{cm} / \mathrm{s})$ and total duration using time and distance the head travels for the duration of a jump. A jump was defined as when the part of the body making static contact that pushed against the substrate actually lifted off the substrate, while the rest of the body progressed forward. Horizontal (lateral displacement), vertical, and resultant distance travelled during the jump by the head was measured. For jumps that resulted in the body completely leaving the ground, we measured the maximal height off the ground of the lowest part of the body and measured horizontal and vertical displacement of the former static push-off point on the tail. For jumps that occurred where at least some of the body did not leave the ground, the maximal proportion of the body length was determined by dividing body length off the ground by total body length. Measurements of distances used for performance and kinematic variables were made during video playback using Quicktime 7 and using screenshots in Image J. Frame size of screenshots was maximized to $1206 \times 904$ pixels (from an original size of $640 \times 480$ pixels) for measuring distances. Distances were determined by measuring the displacement of one point on the body over two screenshots and calibrated using a known distance in the shot (notecard). Screenshot distance measurements were made in Image $J$ and Quicktime 7. Distances for average speed measurements were made from points on the most anterior part of the head. All measurements were made to the nearest $\mathrm{mm}$ by the same individual (EDW). Because of potential error related to this method, we quantified repeatability by taking multiple measurements (at least 5) of the same distances travelled during jumps for three individuals and calculated average deviations. Average deviations for distances measured ranged from $0.40-0.76 \mathrm{~mm}$. Moreover, resolution of images used to determine distances resulted in some error associated with each estimate $(0.525 \mathrm{~mm}$ per pixel). Time measurements were made from time stamp differences.

\section{Statistics}

All jumps for all individuals were combined and were divided into those in which the body completely left the ground (off-jumps) and those that did not (on-jumps). Despite unequal number of jumps among individuals, comparisons between the two aforementioned jumps were made using Mann-Whitney tests for nonnormalized data. We also used paired t-tests to test for differences between distances moved by the head and tail for all jumps. When the data were normally distributed, Z-tests were used to compare these two types of jumps. Linear 
regressions were used to assess the relationships between body mass and for all jumps combined and off-jumps for all individuals combined. However, including all jumps in these models results in some individuals being more represented than others due to the unequal number of jumps among individuals. Therefore, we also conducted linear regressions between mass and the maximum value for each performance variable for each individual $(N=$ 8). All analyses were conducted using the Real Statistics extension for Microsoft Excel.

\section{Results}

Glass lizards jumped by generating and propagating a waveform that moved posteriorly. As their bodies bent, lizards made ground contact with at least one point on their bodies that began at the anterior one-third section of the tail and travelled posteriorly (along with the waveform) during the initiation of a jump. This point of contact would move until a final push off occurred, where a static contact point located roughly in the posterior one-third section of the tail would signal the end of the jump. The body would begin to accelerate off the substrate while the wave and contact point travelled posteriorly. The body would straighten anterior to the static contact point as the force generated against the substrate propelled the body away from the contact point (https://www.youtube.com/ watch?v=ZAeyzCxkv3E). For the one lizard with a broken tail, push off from the substrate occurred using the tip of the tail during two jumps (https://www.youtube.com/watch? $\mathrm{v}=\mathrm{qb}$ _ $\mathrm{Zt0MlCQ).} \mathrm{After} \mathrm{a} \mathrm{few} \mathrm{minutes} \mathrm{following}$ placement in the tank, lizards would cease their attempts to jump. Consequently, not all lizards jumped the same number of times.

Kinematic and performance variables for all jumps combined, jumps that resulted in the body completely lifting off the ground (off-jumps), and jumps in which some proportion of the body remained in contact with the substrate (onjumps) are reported in Table 1. Out of 34 total jump sequences, eight (almost 25\%) resulted in off-jumps. During the on-jumps, an average of $57 \pm 17 \%$ of the body length remained in contact with the ground. Of the eight individuals examined in this study, four individuals were responsible for the eight off-jumps, with one individual with a broken tail exhibiting four offjumps.

Overall, jump durations averaged $0.19 \pm 0.04$ $s$. There were no differences in duration or speed between on- and off-jumps (Mann-Whitney: $p>$ 0.05). However, off-jumps resulted in both larger forward displacement (horizontal) distances (Z-test: $z=-2.44 ; p<0.05$ ) and resultant distances $(z=-2.82 ; p<0.01$; Table 1$)$. There was no difference in vertical distance between on- and off jumps $(z=-1.81 ; p=0.07$; Table 1$)$. We also found no differences in distances travelled between the head and tail (former contact point) for all jumps combined $(p>0.05)$.

Total body mass was not significantly related to duration, vertical distance, horizontal distance, or resultant distance when assessing all jumps or maximum values only (Linear regression: $p>$ $0.05)$. Body mass was positively related to average jump speed $\left(F_{1,32}=10.51 ; p<0.01\right)$ for all jumps combined (Figure 1). However, mass was not significantly related to jump speed $\left(F_{1,6}=3.75 ; p=0.101\right)$ when only maximal jumps were used in regressions. For off-jumps, mass was positively related to jump speed $\left(F_{1,6}=11.99 ; p=0.013\right)$.

\section{Discussion}

We observed that glass lizard saltation occurred by accelerating the head, which generated a sine wave (i.e. lateral bend) that propagated posteriorly while force was simultaneously produced by pushing off the substrate with the posterior half of the tail that bent to make static contact. The individual with a broken tail would push off using the tail tip. This mechanism appears to be similar to that reported in one other limbless lizard (Delma tincta), which was described as using a modified 
Table 1. Summary data for jump sequences of eight Western Slender Glass Lizards (Ophisaurus attenuatus). Jumps were divided into those in which the body completely lifted off the substrate (Off-Jumps) and those in which at least some portion of the body remained in contact with the substrate (On-Jumps). Maximal jumps represent the maximum value for each individual. All speed and distance values have a potential error of at least $0.525 \mathrm{~mm}$ due to resolution of images used to calculate distances. Values are given as mean $\pm \mathrm{SD}$. NA $=$ not applicable.

\begin{tabular}{lcccc}
\hline Variable & Off-Jumps & On-Jumps & All Jumps & Maximal Jumps \\
\hline Total number & 8 & 26 & 34 & 8 \\
Speed $(\mathrm{cm} / \mathrm{s})$ & $6.18 \pm 2.38$ & $6.06 \pm 2.69$ & $6.09 \pm 2.51$ & $6.83 \pm 3.17$ \\
Horizontal distance $(\mathrm{cm})$ & $17.51 \pm 8.12$ & $10.79 \pm 6.92$ & $12.37 \pm 7.55$ & $19.77 \pm 6.76$ \\
Vertical distance $(\mathrm{cm})$ & $21.73 \pm 7.93$ & $15.97 \pm 6.34$ & $17.32 \pm 7.07$ & $23.40 \pm 5.24$ \\
Resultant distance $(\mathrm{cm})$ & $29.25 \pm 6.41$ & $20.39 \pm 6.47$ & $22.49 \pm 7.34$ & $28.56 \pm 5.94$ \\
Duration (s) & $0.21 \pm 0.03$ & $0.18 \pm 0.04$ & $0.19 \pm 0.04$ & $0.20 \pm 0.02$ \\
Proportion of body length off ground & $\mathrm{NA}$ & $0.57 \pm 0.17$ & $\mathrm{NA}$ & $0.85 \pm 0.19$ \\
Height off ground $(\mathrm{cm})$ & $3.19 \pm 2.22$ & $\mathrm{NA}$ & $\mathrm{NA}$ & $\mathrm{NA}$ \\
\hline
\end{tabular}

waveform from lateral undulation and using the tail for force generation (Bauer 1986). The kinematic pattern we observed in $O$. attenuatus seemingly differs from that of snakes, which has been described as a modified form of sidewinding or concertina involving the formation of several tight $\mathrm{S}$-curves and then propelling the head and body forward (Gans 1974, Bartholomew and Nohavec 1995). Since jumping in snakes resembles an exaggerated strike that creates enough momentum to lift the body off the substrate (Lillywhite 2014), it always results in lateral displacement (Gans and Mendelssohn 1972, Bartholomew and Nohavec 1995). Saltation by limbless lizards also differs from snakes in that lateral displacement may or may not occur. It is also interesting to note that the contribution of the tail to jumping likely differs between limb-reduced lizards and snakes. Many limbless lizards have tails that are often greater than twice their snout-vent length, whereas the relative length of the tail in snakes is often less than 10\% snout-vent length (Pianka and Vitt 2003). This suggests that the tail of a limbless lizard might play a larger role in wave

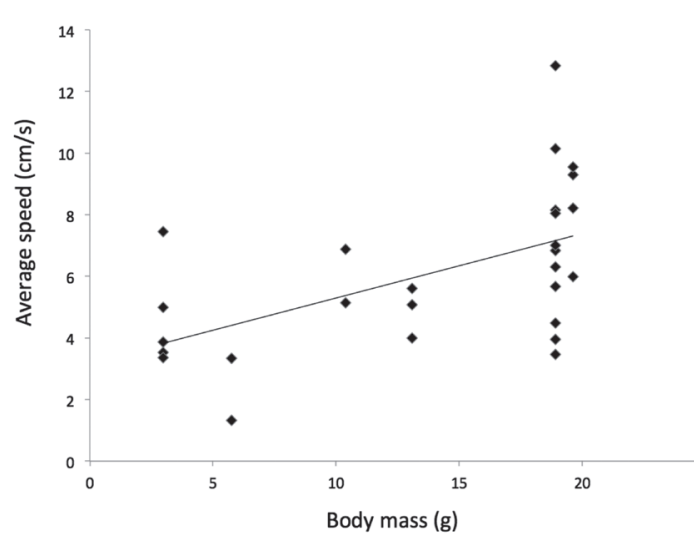

Figure 1. Influence of body mass on average speed of the head during saltation sequences measured in eight individual Western Slender Glass Lizards (Ophisaurus attenuatus).

propagation and the anchoring needed for force generation than in snakes.

Jump durations of $O$. attenuatus (Table 1) were roughly half that reported in the two jump sequences ( 0.41 and $0.45 \mathrm{~s})$ analysed in $D$. tincta. Despite this difference, the height of the 
body off the ground during off-jumps (Table 1) in our study was similar to that reported in $D$. tincta (3 and $7 \mathrm{~cm}$; Bauer 1986). Although there were no significant differences in duration or speed between on- and off-jumps, on-jumps did result in further distance travelled. This suggests that the amount of force generation is the sole factor that determines whether or not the lizard completely lifts the entire body off the substrate during the jump. It is also possible that higher speeds and durations (though not significant; Table 1), can result in significant differences in jump distances. The use of non-parametric tests makes it difficult to conclude the exact cause of these potential differences.

We also examined the influence of body size on various characteristics of saltation. In most animals, performance scales allometrically with body size, with larger animals exhibiting superior performance (Schmidt-Nielsen 1984, Arnold and Bennett 1988). Despite the finding that larger lizards exhibited faster speeds when examining all jumps combined, this did not result in larger distances jumped. Gans and Mendelssohn (1972) found that only smaller individual vipers (Bitis caudalis) $(<23.5 \mathrm{~g})$ were able to jump off the substrate. It was concluded that larger individuals were not able to generate enough velocity to counteract the effect of gravity on a larger body mass. Our finding that larger individuals achieved faster performance (speed) without a commensurate increase in jump distances suggests that both the increasing efficiency of muscle contractions and increasingly hindering effects of gravity with increases in body mass determine jumping abilities in limbless reptiles. However, it is important to note that this relationship was not significant when assessing only maximal jumps for each individual, which suggests that the seemingly superior jumping performance of certain individuals confounds this analysis.

When fleeing is not a viable option, saltation in limbless reptiles appears to be an anti-predator behavioral strategy used to escape, frighten, or distract potential predators. With some exceptions (e.g., flying snakes), saltation is not typically used for forward movement. The lack of lateral displacement in some jump sequences observed in both $O$. attenuatus and D. tincta support this notion (Bauer 1986). It is unknown how successful saltation is at thwarting predation. It is interesting to note that the individual with the broken tail in this study jumped higher and more often than those with intact tails. Moreover, the propagating wave (i.e. lateral bends) generated by this individual terminated at the tip of the tail, which was used as a static contact point to, seemingly, generate more force. Though this difference could reflect individual variation in jumping behaviour, this individual may have displayed superior jumping performance because it experienced more stress (e.g., predation attempts) prior to the study and, hence, was more motivated to escape. Its broken tail may have also facilitated longer jumps (i.e., more force). Broken tails are very common in glass lizards and other limbless lizards (Fitch 1989, Pianka and Vitt 2003) and are likely indicative of high rates of predation attempts. Future studies should more closely examine the utilization of the tail during saltation in limbless lizards and attempt to correlate jumping behaviors with survival in nature.

\section{Acknowledgments}

We would like to thank Michael Graziano for assistance with the collection of lizards for this study. Lisette E. Torres provided helpful comments that improved this manuscript. A research permit to collect glass lizards was issued to Gary W. Gerald by the state of Kansas, U.S.A. (permit \#SC-105-2011). Funding for this project was partially provided by grants from the National Center for Research Resources (5P20RR016469) and the National Institute for General Medical Science (NIGMS) (5P20GM103427), a component of the National Institutes of Health (NIH). This study was approved by the Nebraska Wesleyan University Institutional Animal Care and Use Committee (\#01-002255). 


\section{References}

Arnold, S. J. and A. F. Bennett. 1988. Behavioural variation in natural populations. V. Morphological correlates of locomotion in the garter snake (Thamnophis radix). Biological Journal of the Linnean Society 34: 175-190.

Bauer, A. M. 1986. Saltation in the pygopodid lizard, Delma tincta. Journal of Herpetology 20: 462-463.

Bartholomew, B. and R. D. Nohavec. 1995. Saltation in snakes with a note on escape saltation in a Crotalus scutulatus. Great Basin Naturalist 55: 282-283.

Cliburn, J. W. 1957. Leaping ability of the glass lizard. Herpetologica 13: 24.

Fitch, H. S. 1989. A field study of the slender glass lizard, Ophisaurus attenuatus, in northeastern Kansas. Occasional Papers of Natural History Museum, University of Kansas 125: 1-50.

Gans, C. 1974. Biomechanics: An Approach to Vertebrate Biology. Ann Arbor. University of Michigan Press. 261 pp.

Gans, C. and H. Mendelssohn. 1972. Sidewinding and jumping progression of vipers. Pp. 17-38 in A. de Vries and E. Kochva (eds.), Proceedings of the Second International Symposium on Toxins of Animal and Plant Origin. London. Gordon and Breach.

Lillywhite, H. B. 2014. How Snakes Work: Structure, Function, and Behavior of the World's Snakes. Oxford. Oxford University Press. 256 pp.
Losos, J. B. and D. J. Irschick. 1996. The effect of perch diameter on escape behavior of Anolis lizards: laboratorybased predictions and field tests. Animal Behaviour 51: 593-602.

Mattingly, W. B. and B. C. Jayne. 2004. Resource use in arboreal habitats: structure affects locomotion of four ectomorphs of Anolis lizards. Ecology 85: 1111-1124.

Pianka, E. R. and L. J. Vitt. 2003. Lizards: Windows to the Evolution of Diversity. Berkeley. University of California Press. 348pp.

Schmidt-Nielsen, K. 1984. Scaling: Why is Animal Size so Important? Cambridge. Cambridge University Press. $256 \mathrm{pp}$.

Socha, J. J. 2006. Becoming airborne without legs: the kinematics of take-off in a flying snake, Chrysopelea paradisi. Journal of Experimental Biology 209: 33583369 .

Socha, J. J. 2011. Gliding flight in Chrysopelea: turning a snake into a wing. Integrative and Comparative Biology 51: 969-982.

Toro, E., A. Herrel, and D. J. Irschick. 2004. The evolution of jumping performance in Caribbean Anolis lizards: solutions to biomechanical trade-offs. American Naturalist 163: 844-856.

Editor: Jaime Bertoluci 